\title{
Effects of Different Taping Pressures of Wrist Taping Using Rigid Tape on Grip Strength Exertion
}

\author{
Kenji Takahashi, ${ }^{1, *}$, Shin-ichi Demura \\ ${ }^{1}$ Faculty of Community Health Care, Department of Judo Physical Therapy, Teikyo Heisei University, Uruidominami 4-1 Ichihara, \\ Chiba, Japan \\ ${ }^{2}$ Graduate School of Natural Science \& Technology, Kanazawa University, Kakuma, Kanazawa, Ishikawa, Japan \\ *Corresponding author: kenji.takahashi@thu.ac.jp
}

Received August 05, 2014; Revised October 21, 2014; Accepted November 23, 2014

\begin{abstract}
In general, wrist taping is performed using a rigid tape. The present study aimed to examine the effect on grip strength exertion due to different taping pressures on the wrist joint using rigid tape. Subjects were 25 male university students (mean age, $20.2 \pm 0.8$ years) with over 5 years of athletic experience. The wrists of the subjects were taped using one piece of rigid tape wound three times around the wrist joint, including the radial and ulnar styloid processes. Furthermore, taping pressure was adjusted by the pressure measuring system AMI3037-SB, and the sensor was set on the palmaris longus muscle tendon of the dominant wrist. Independent variables included four taping pressure conditions (5, 30, 60, and $90 \mathrm{hPa}$ ) and a control (no tape) condition. Statistical analysis showed that grip strength exertion was significantly lower in the $90 \mathrm{hPa}$ condition than in the control condition, but the difference was small (effect size $=0.26$ ). In conclusion, wrist taping pressure conditions lower than $60 \mathrm{hPa}$ had little effect on grip strength exertion. However, pressure conditions of $90 \mathrm{hPa}$ slightly decreased grip strength and may interrupt blood flow.
\end{abstract}

Keywords: pressure measuring device, blood flow, wrist joint

Cite This Article: Kenji Takahashi, and Shin-ichi Demura, "Effects of Different Taping Pressures of Wrist Taping Using Rigid Tape on Grip Strength Exertion.” American Journal of Medical Sciences and Medicine, vol. 2, no. 6 (2014): 122-125. doi: 10.12691/ajmsm-2-6-2.

\section{Introduction}

Wrist injuries and disorders occur frequently in sports that impose a large load on the wrist joint such as in gymnastics and in contact sports, such as judo, wrestling, and sumo, where the wrist joint is strongly twisted by various external forces [1]. Not only athletes but also many people in the general population develop injuries of the wrist joint [2]. This can occur when a person unintentionally puts his/herhand on the ground to supportthe body while falling. Wrist injury is generally caused by excessive dorsal flexion [3]. Consequently, the wrist joint is fixed using a tape and splints. In short, fixation of the wrist joint aims to prevent wrist disorders or injuries by limiting excessive wrist motion [4,5].

However, wrist taping has been reported to decrease strength exertion and motor performances. Kauranen et al. [6] reported that wrist taping decreases motor performances, such as simple reaction time, choice reaction time, and tapping speed, in addition to isokinetic strength exertion during wrist palmar and ulnar flexion. Rettig et al. reported that separate taping of the fingers or wrist joint does not affect grip strength, but taping the fingers and wrist together decreases it;from this study [7], it was inferred that grip strength exertion decreases by strengthening the taping pressure, even when only the wrist is taped.
Tapes used for preventing injuries of the wrist joint include rigid tape, elastic tape, or both [4]. In general, the rigid tape is used to limit movement and the elastic tape is used to compress and support soft tissues [5], thereby differing in purpose and effect. Takahashi et al. [8] reported that wrist-taping pressure of over $30 \mathrm{hPa}$ using elastic tape slightly decreases grip strength exertion. However, little is known regarding the effect of rigid tape on grip strength exertion using different taping pressures around the wrist joint.

Constantinou and Brown [4] highlighted the necessity of taping pressure after reviewing previous studies examining the effects of taping. Even when using the same taping method, the effects on strength exertion may vary according to different taping pressures. Wilson et al. [9] and Pfeiffer et al. [10] reported that employing a qualified trainer can help to control the performer's effect. In the present study, a qualified practitioner performed taping and adjusted the tape pressure. In our previous study [8], grip strength exertion was shown to decrease when elastic tape pressure was greater than $30 \mathrm{hPa}$. Hence, we hypothesized that even when using rigid tape, wrist taping with pressure greater than $30 \mathrm{hPa}$ would decrease grip strength exertion.

The present study aims to examine the effects of maximum grip strength using different taping pressures around the wrist using a rigid tape. 


\section{Methods}

\subsection{Participants}

Subjects were 25 male university students (mean age, $20.2 \pm 0.8$ years) with over 5 years of athletic experience and without history of wrist injuries, such as serious sprains, fractures, or dislocations. Subjects were classified on the basis of their participation in sportsas follows: baseball $(n=9)$, soccer $(n=7)$, badminton $(n=2)$, basketball $(n=1)$, judo $(n=1)$, kendo $(n=1)$, longdistance running in track and field $(\mathrm{n}=1)$, sprint in track and field $(n=1)$, swimming $(n=1)$, and tennis $(n=1)$.

The basic characteristics of the subjects were as follows: age, height, body weight, body mass index, wrist circumference, and competitive sports experience (Table 1).

Table 1. Data pertaining to age, height, body weight, body mass index, circumference of the dominant wrist joint, and sports experience of the subjects

\begin{tabular}{|c|c|c|}
\hline $\mathrm{n}=25$ & $\mathrm{M}(\mathrm{SD})$ & Range (minimum-maximum) \\
\hline Age (years) & $20.2(0.8)$ & $18-22$ \\
\hline Height (cm) & $170.4(6.2)$ & $158.5-183.4$ \\
\hline Weight (kg) & $65.6(9.4)$ & $53.1-91.1$ \\
\hline Body mass index & $22.6(2.8)$ & $18.1-30.8$ \\
\hline Wrist circumference of the dominant hand (cm) & $16.0(0.7)$ & $14.2-17.0$ \\
\hline Sports experience (years) & $8.0(1.8)$ & \\
\hline
\end{tabular}

The aim and procedures of the present study were explained in detail to all subjects before conducting the experiments, and written informed consent was obtained. This experimental protocol was approved by the Ethics Committee on Human Experimentation of the Faculty of Human Science, Kanazawa University (2012-18).

\subsection{Examiner (Taping Examiner)}

A qualified athletic trainer (certified by the Japan Sport Association) with clinical experience of over 10 years performed the taping and adjusted the tape pressure.

\subsection{Devices}

\subsubsection{Rigid Tape (Non-elastic Taping)}

In the present study, we used a 50-mm rigid (nonelastic) tape manufactured by Johnson \& Johnson (New Brunswick, NJ, USA).

\subsubsection{Pressure Measuring Device}

Taping pressure was measured using the pressure measuring system for stockings and bandages (AMI3037SB, AMI-Techno, Tokyo, Japan; Figure 1). This system can measure pressure on the human body through clothing such as socks [11]. Therefore, this device is considered to be useful for measuring taping pressure. The measurement unit was hPa. A measurable range was $1-200 \mathrm{hPa}$, and the measurement error was $\pm 3 \mathrm{hPa}$.

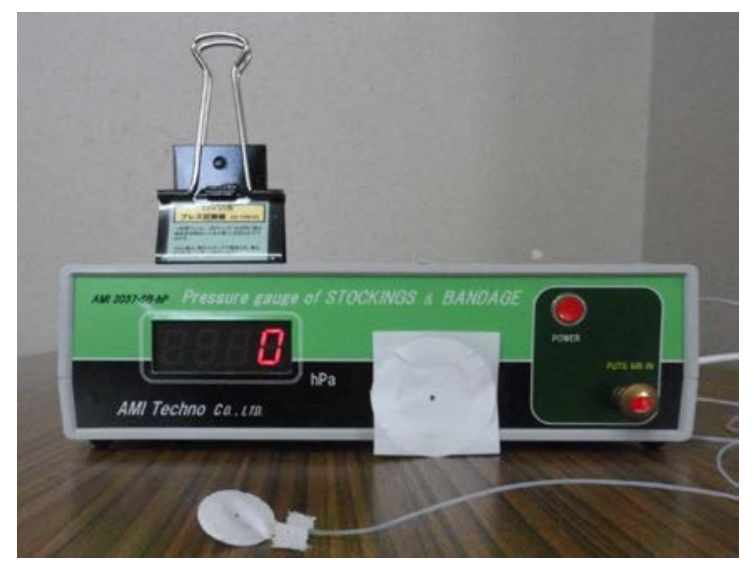

Figure 1. Pressure measuring system for stocking and bandages (AMI3037-SB)

\subsubsection{Measurement of Grip Strength}

Grip strength was measured using a grip strength dynamometer (T.K.K. 5401 Grip-D, Takei, Tokyo, Japan) with the subject positioned in the following sitting posture: shoulder joint $30-60^{\circ}$ forward flexion, elbow joint $15-30^{\circ}$ flexion, and forearm in the middle position between pronation and supination based on the manufacturer's manual. The measurement unit was kg.

\subsection{Wrist Taping Method}

The wrist was taped three times around the joint at the radial and ulnar styloid process using one piece of rigid tape (Figure 2). Although there are several techniques used for taping, the aforementioned method was deemed suitable to control taping pressures.

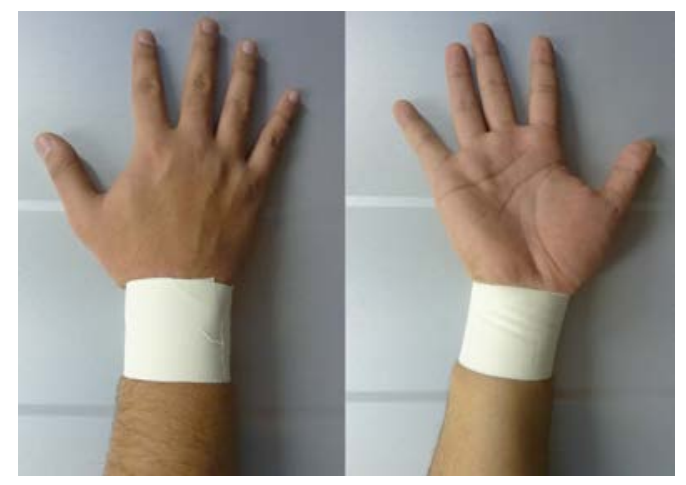

Figure 2. Wrist taping method

\subsection{Independent and Dependent Variables}

Based on our previous study [8], five experimental conditions were set as independent variables: four taping pressure conditions (5, 30, 60, and $90 \mathrm{hPa}$ ) and a control condition (no tape). A taping pressure condition of 120 $\mathrm{hPa}$ by rigid tape was excepted because of the large burden of pain for subjects. Further, the dependent variable was the larger value of thetwo grip strength measurements.

\subsection{Procedure}

In the present study, the dominant hand of subjects was selected for testing. The dominant hand was determined according to Demura's handedness inquiry[12]. Before 
starting the experiment, subjects performed wrist warm-up exercises to prevent injury. A pressure sensor was placed over the palmaris longus muscle tendon $1.5 \mathrm{~cm}$ proximal to the palmar crease of the wrist (Figure 3-a) and was fixed using a cover tape (Figure 3-b). Subsequently, the wrist was taped (Figure 3-c). Taping pressure was adjusted while being monitored by a pressure measuring device. Because it is difficult to precisely measure the initial taping pressure, the 5- hPa condition was adjusted within a range of $\pm 1 \mathrm{hPa}$, and the other pressure conditions were adjusted within a range of $\pm 2 \mathrm{hPa}$.

Grip strength was measured twice in each experimental condition with a rest time of more than 2 min between trials. Taping pressure conditions and the control condition were randomized for every subject, and each subject was measured for only one condition/day. Subjects were tested between 9:00 and 13:00 in a laboratory room, with temperature being maintained at $26^{\circ} \mathrm{C}$.

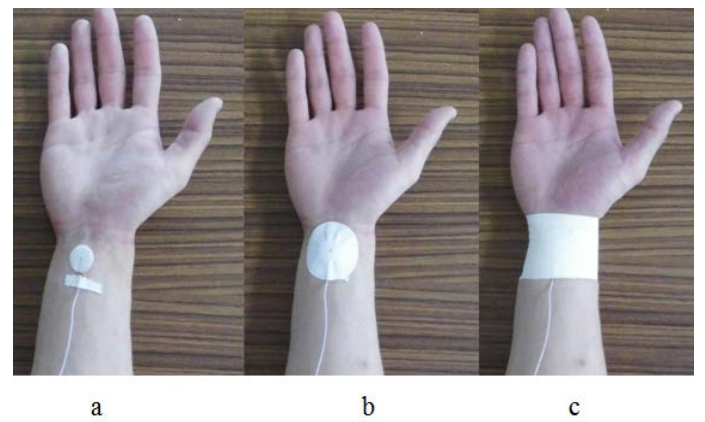

Figure 3. Pressure sensor set on the Palmaris longus muscle tendon

a: pressure sensor only

b: pressure sensor + cover tape

c: pressure sensor + cover tape + wrist taping

\subsection{Statistical Analysis}

One-way repeated measures analysis of variance (ANOVA) was used to reveal the differences between the means of each condition. When a difference was found, a multiple comparison test was performed using Tukey's honestly significant difference method. Statistical significance $(\alpha)$ was set at $p<0.05$. An effect size (ES) was calculated to examine the size of the mean difference. ES was interpreted as follows: $<0.2$ (small), $>0.5$ (intermediate), and $>0.8$ (large).

\section{Results}

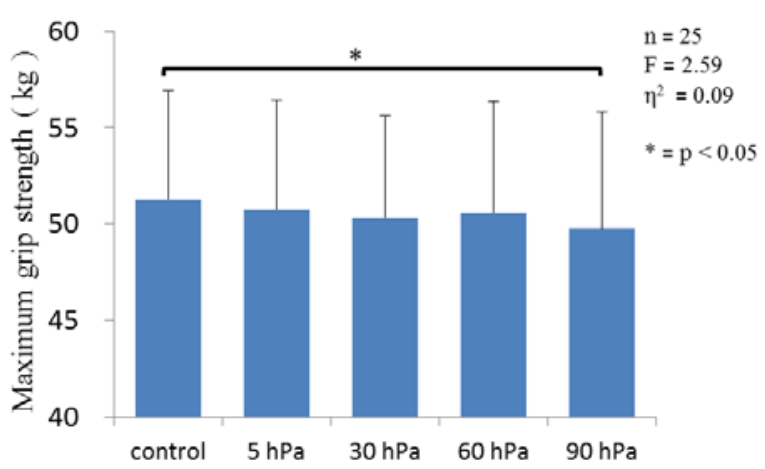

Figure 4. Means and standard deviations of grip strength exertion in five conditions and the results of a one-way repeated measures analysis of variance
Figure 4 shows the means and standard deviations of grip strength exertion in each condition and the results of the one-way repeated measures ANOVA and multiple comparison tests. A significant main effect was observed: $\mathrm{F}=2.59, \mathrm{p}<0.05, \eta^{2}=0.09$. Multiple comparison tests showed that grip strength in the $90-\mathrm{hPa}$ condition was significantly smaller than that in the control condition;however, the difference was small ( $E S=0.26$ ).

\section{Discussion}

The present results suggest that rigid-tape wrist taping cannot enhance grip strength exertion but rather slightly limits it when the taping pressure is $90 \mathrm{hPa}$. In our previous study using elastic tape [8], taping pressure of over $30 \mathrm{hPa}$ decreased grip strength exertion. Hence, we hypothesized that taping pressure ofover $30 \mathrm{hPa}$ using rigid tape restricts grip strength exertion. However, this hypothesis was rejected. In brief, even taping pressures of 30 and $60 \mathrm{hPa}$ did not decrease grip strength values.

This is considered to be due to the difference in tape materials. Internal pressure inthe wrist joint increases by grip strength exertion[13]. Taping pressure on the wrist joint also increases by increasing internal pressure. In the case of elastic tape, it is considered that taping pressure is intensified by grip strength exertion because the tape shrinks when pressure is added. Because the rigid tape is not capable of shrinking, it may not have an effect on force exertion like an elastic tape. In short, it is postulated that when pressure around the wrist joint is enhanced over a certain level by taping, grip strength exertions in addition to tendon movement is limited.

Grip strength exertion was slightly limited only in the 90-hPa condition (ES = 0.26). Cordova et al. [14] reported that sprint speed, vertical jump, and agility speed were limited by approximately $0.5 \%-1.0 \%$ with ankle taping, and highlighted that taping should be used whileconsidering the benefits of the injury and disorder prevention and the demerits. For instance, although track and field sprinters should consider the use of ankle taping to maintain sprint speed, track and field throwers may be careless about it because taping has little effect on their performance.

Similarly, wrist taping in competitive sports,such as judo, requires large grip strength exertion, and it should be considered whether to assign priority to prevent injuries and disorders or to exert the grip strength. Therefore, the present study results can serve as a judgment criterion when selecting the taping pressure.

Wrist taping under high-pressure conditions is required to strongly limit the range of motion of the wrist $[15,16]$. Thus, wrist taping with strong pressures, such as $90 \mathrm{hPa}$,is expected to prevent injuries and disorders.

However, it should be noted that strong fixation of the wrist considerably limits the motion of the wrist joint and limits the wrist motion required during competitive sports. In addition, prolonged high pressure taping, such as over $40 \mathrm{mmHg}(=53 \mathrm{hPa})$, has negative effects that cause blood circulation disorders due to congestion [17]. A slight pressure change of $1-3 \mathrm{hPa}$ in the heartbeat and a reddishblack change of finger complexion were observed in all subjects during the $90-\mathrm{hPa}$ condition in this experiment. This may result when the taping pressure rises above the 
diastolic blood pressure. A prolonged pressure of above $60 \mathrm{hPa}$ has many negative effects such as muscle temperature decline and sensory impairment due to constricted blood flow [18]. Therefore, wrist taping with over $90 \mathrm{hPa}$ of pressure may cause problems for athletes participating in events with long competition times.

From the present results, we show that wrist taping with over $90 \mathrm{hPa}$ of pressure using rigid tape would be desirable to avoid negative effects on grip strength exertion and blood flow.

As practical applications to competitive sports, taping pressure should be set at $<60 \mathrm{hPa}$ in athletic events wherein grip strength exertion affects athletic performances. Conversely, in athletic events wherein grip strength exertion is not required and the performance time is short, it is thought that adding taping pressure of $90 \mathrm{hPa}$ is effective in preventing injury.Therefore, it is necessary to adjust taping pressure according to the sport and duration of the competition.

There are some methods of wrist taping other than that used in this study [5]. Therefore, it is considered that the effect of taping pressure differs with the taping method.One limitation of the study is that the results apply only to the taping method used in this study.

Not only grip strength but also dynamic muscle strength of wrist dorsal and palmar flexion affects athletic performances. In future, it is necessary to consider the appropriate taping pressureon dynamic muscle strength after examining the effects of wrist taping with different taping pressures.

\section{Conclusions}

Wrist taping using rigid tape does not enhance grip strength exertion, but wrist taping with $90 \mathrm{hPa}$ of pressure slightly limits grip strength exertion. In addition, there is also a possibility of obstructing blood flow around the wrist joint with $90 \mathrm{hPa}$ of pressure. Hence, based on the effects of grip strength exertion and blood flow disorder, it is adequate touse pressure of less than $90 \mathrm{hPa}$ when performing wrist taping using rigid tape.

\section{References}

[1] Ronald L, James H. Athletic injuries of the wrist. Clinical Orthopedics\& Related Research 198: 141-151, 1985

[2] Laura A, Robin J, Erica K, Jeffery M. Falls in young, middle-aged and older community dwelling adults: perceived cause, environmental factors and injury. BMC Public Health 5: 862005

[3] Rettig A: Athletic Injuries of the Wrist and Hand Part II: Overuse Injuries of the Wrist and Traumatic Injuries to the Hand. Am J Sports Med 32 (1): 262-273, 2004.

[4] Constantinou M, Brown M: Therapeutic taping for musculoskeletal conditions. Elsevier: Churchill Livingstone, 2010.

[5] Rose M: In Pocketbook of Taping Techniques, 1st ed., Elsevier, Churchill Livingstone 2010, (178-181).

[6] Kauranen K, Siira P, Vanharanta H. The effect of strapping on the motor performance of the ankle and wrist joints. Scand J Med Sci Sports 7: 238-243, 1997.

[7] Rettig A, Stube K, Shelbourne K. Effects of finger and wrist taping on grip strength. Am J Sports Med 25 (1): 96-98, 1997.

[8] Takahashi K, Demura S, Noguchi T, Demura G, Xu Ning. Effects of elastic wrist taping on maximum grip strength. Am J Sports Sci and Med 1 (3): 33-36, 2013.

[9] Wilson T, Carter N, Thomas G: A multicenter, single-masked of medial, neutral, and lateral patellar taping in individuals with patellofemoral pain syndrome. J Orthop Sports Phys Ther 33 (8): 437-448, 2003.

[10] Pfeiffer RP, DeBeliso M, Shea KG, Kelley L, Irmischer B, et al. Kinematic MRI assessment of McConnell taping before and after exercise. Am J Sports Med 32 (3): 621-628, 2004.

[11] Ooizumi Y, Matsuzawa E, Iida Kenichi: Establishment of evaluation methods of clothing pressure of high supported clothesthe relation between clothing pressure of stretch clothes measured on a dummy and the human body [in Japanese]. Bulletin of TIRI 2: 120-121, 2007.

[12] Demura S, Sato S, and Nagasawa Y: Reexamination of useful items for determining hand dominance [in Japanese]. Arch Sci Med (Torino) 168: 169-177, 2009.

[13] Yamaji S, Demura S, Nagasawa Y, Nakada M: Relationships between decreasing force and muscle oxygenation kinetics during sustained static gripping. Applied Human Science 23: 41-47, 2004.

[14] CordovaML, ScottBD, IngersollCD, LeblancMJ: Effects of ankle support on lower-extremity functional performance. Med \& Sci in Sports \& Execise 37 (4): 635-641, 2005.

[15] Takahashi K,Demura S. Effects of wrist taping pressures on the maximum dorsal flexion angle.Am J Sports Sci and Med 2 (4): 143-147, 2014.

[16] Takahashi K,Demura S,Yamaji S, Noguchi T. Effects of wrist taping with pressure on the palmar flexion range of motion (Abstract). The Journal of Education \& Health Science: 15th Japan and Korea, education and health science symposium program 59 (1): 95, 2013.

[17] Hirai M: Elastic stockings and intermittent pneumatic compression in the prevention of deep vein thrombosis and pulmonary embolism [in Japanese]. Japanese Journal of Phlebolgy 14 (1): 49-62, 2003.

[18] HirataK, Yoshida M.Effect of cuff compression intensity and cuff width on Skin blood flow measured by a laser-Doppler flow meter. [in Japanese]. J JRA for Textile End-Use 36: 154-161, 1995. 